\title{
The lived experience of Cauda Equina Syndrome: a qualitative analysis
}

\author{
$\mathrm{R} \mathrm{Hall}^{1}$ and K Jones ${ }^{2}$
}

Study design: An exploratory qualitative analysis, using semi-structured interviews to investigate the lived experience of Cauda Equina Syndrome (CES).

Objectives: To address the paucity of psychological research into CES and explore patient experiences of living with the injury. Setting: The study was conducted in the United Kingdom. Recruitment was via two National Health Service spinal services in the South East of England and an online CES charity.

Methods: An interpretative phenomenological analysis (IPA) methodology was employed. Eleven participants took part in the study and completed an interview consisting of seven open ended questions relating to the psychosocial impact of CES. Interviews were audio-recorded, transcribed verbatim and analysed following an IPA procedure.

Results: Three superordinate themes were generated. The first, Dissatisfaction with care: '/ felt very abandoned', captured experiences of feeling neglected and disbelieved by the healthcare system and a wish for symptoms to be validated. The second, Hidden to others: 'Nobody knows. It's horrible', spoke to a struggle to gain a social identity in relation to a hidden disability. The third, Changing identities: 'You become someone totally totally different' versus 'You're still the same person', captured a process of renegotiating identity following CES.

Conclusion: Findings highlight the importance of improving access to support for people with CES, as well as validating and facilitating disclosure of hidden symptoms. There is a clear need for more research into the psychosocial impact of this injury.

Spinal Cord (2018) 56, 41-45; doi:10.1038/sc.2017.92; published online 8 August 2017

\section{INTRODUCTION}

Cauda Equina Syndrome (CES) is a condition closely related to spinal cord injury (SCI) characterised by core symptoms of bladder, bowel and sexual dysfunction, and pain. Individuals who live with this condition can usually walk - this is due to injury occurring at the base of the spinal cord - although people with CES may still experience changes to their mobility. To date, there is a paucity of research into the psychological impact of CES. To the authors knowledge, only one article, ${ }^{1}$ framed within a physiotherapy perspective, has investigated the experience of living with the condition. This lack of research is concerning given that the core symptoms of CES (bladder, bowl and sexual dysfunction) are consistently reported by individuals with SCIs as the most distressing aspects of injury, and their most important health priorities, over and above issues relating to mobility. ${ }^{2}$ While there is a wide range of psychological research pertaining to $\mathrm{SCIs},{ }^{3-5}$ the lack of CES-specific research has led to a failure to capture a nuanced account of patients' experiences of the condition and the potential impact of distinct features, such as experiencing internal symptoms of a SCI while being able to walk.

Regarding diagnosis and intervention, CES is confirmed upon MRI, with diagnostic accuracy being poor prior to this confirmation. ${ }^{6}$ When identified, it is treated as a surgical emergency; however, there are no UK national guidelines to mediate post-surgical follow-up. While National Health Service (NHS) England has outlined a SCI service specification $^{7}$ and the National Institute for Health and Clinical Excellence provides guidelines for the assessment and management of SCIs, ${ }^{8}$ neither specify what psychosocial support should be provided post injury. Anecdotal reports from clinicians working in SCI settings in the United Kingdom suggest that individuals with CES struggle to access appropriate and timely pre- and post-diagnostic support, and whether connected or not, it is noteworthy that CES is associated with disproportionally high levels of litigation and successful claims against the NHS, when compared with other conditions. ${ }^{9}$ According to Daniel et al.'s review of medico legal cases, litigation risk is positively associated with delays in diagnosis and surgical intervention, with severity of symptoms not impacting on verdicts.

Given that CES presents significant challenges both to individuals themselves, and the NHS in terms of litigation costs, it is of upmost importance to understand patient experiences of the condition. This study aimed to address this by asking the following research question: What are the lived experiences of individuals with CES?

\section{METHODS}

The study employed an interpretative phenomenological analysis (IPA) methodology as outlined by Smith, Flowers and Larkin. ${ }^{10}$ This qualitative approach provides a systematic method for understanding people's experience of a particular phenomenon, and is well suited to under researched groups. Participants were recruited from a pool of outpatients during routine clinical

${ }^{1}$ Oxford Institute of Clinical Psychology Training, University of Oxford, Oxford, UK and ${ }^{2}$ Department of Clinical Psychology, National Spinal Injuries Centre, Stoke Mandeville Hospital, Aylesbury, UK

Correspondence: Dr K Jones, Department of Clinical Psychology, National Spinal Injuries Centre, Stoke Mandeville Hospital, Mandeville Road, Aylesbury HP21 8AL, UK.

E-mail: Kevin.jones@buckshealthcare.nhs.uk

Received 6 April 2017; revised 22 June 2017; accepted 23 June 2017; published online 8 August 2017 


\section{Table 1 Interview schedule}

\section{Questions}

1. Can you briefly tell me about your experience of receiving your CES diagnosis?

2. How do you feel about having CES?

3. How does CES affect your life?

4. How have you managed life with CES?

5. Has the way you see yourself changed since your injury?

6. Has your experience of living with CES changed over time?

7. Is there anything else you would like to say about your experiences of living with CES?

contact from two NHS spinal injury rehabilitation services in the South East of England, and via an advertisement on the website of the Cauda Equina Syndrome UK charity (CES-UK). Participants were required to have been diagnosed with CES (complete or incomplete) for at least 1 year, be aged 18 or over and fluent in English. All participants self-identified as having CES, and their diagnosis was confirmed by either the referring NHS clinician, or GP in cases recruited from CES-UK. All participants were offered the option of face to face or Skype interviews. The latter aimed to increase access to participation, with both mediums deemed comparable and valid ways of conducting interviews. $^{11}$

All participants were reimbursed $£ 20$ following completion of a short demographics and injury characteristics questionnaire and a semi-structured interview developed by the authors, which consisted of seven open-ended questions relating to people's experience of living with CES (Table 1).

Interviews lasted between 60 and $90 \mathrm{~min}$ were audio recorded and transcribed verbatim. In line with the IPA method, ${ }^{10}$ transcripts were coded by the first author based on the researcher's interpretation of the participant's objects of concern and experiential claims. These codes were clustered into emerging themes for each transcript. Similarities and differences were then compared across transcripts to create subordinate themes and subsequently grouped into superordinate themes.

Data were triangulated through discussions among both authors and an independent IPA expert. This helped to deepen the exploration of the data and check validity of superordinate themes. The first author completed a bracketing interview and kept a reflective journal in order to consider how her own assumptions and beliefs may have influenced data collection and analysis.

We certify that all applicable institutional and governmental regulations concerning the ethical use of human volunteers were followed during the course of this research.

\section{RESULTS}

Eleven participants took part in the study; six women and five men, with a mean age of 47.3 years (s.d. 8.1; Table 2). All participants' lesions were incomplete and most reported a prolapsed disc as the cause of CES, apart from James who reported a fall-exact aetiology unclear. Two participants (Catherine and Michael) were recruited from the CES-UK website and had received post-surgical support in primary care only; they also happened to have had their injury considerably longer than other participants. All others were recruited via NHS sites and had undergone inpatient rehabilitation on a spinal unit. Pseudonyms are throughout the article to preserve participant anonymity.

Three superordinate themes were generated from the data, each with three to four subordinate themes (Table 3).

\section{Dissatisfaction with care: 'I felt very abandoned'}

This superordinate theme relates to participants' experience of feeling neglected and disbelieved by healthcare professionals. This was associated with feelings of anger and injustice. The final subordinate
Table 2 Participant demographics and clinical characteristics

\begin{tabular}{|c|c|c|c|c|c|c|}
\hline $\begin{array}{l}\text { Participant } \\
\text { (pseudonym) }\end{array}$ & Gender & Age & $\begin{array}{l}\text { Relationship } \\
\text { status }\end{array}$ & $\begin{array}{c}\text { Employment } \\
\text { status }\end{array}$ & $\begin{array}{c}\text { Time since } \\
\text { diagnosis } \\
\text { (years) }\end{array}$ & $\begin{array}{c}\text { Level } \\
\text { of } \\
\text { injury }\end{array}$ \\
\hline Sally & Female & 41 & Single & Unemployed & 1.9 & L5-S1 \\
\hline Dawn & Female & 49 & $\begin{array}{l}\text { In } \\
\text { relationship }\end{array}$ & Full time & 1.5 & L1 \\
\hline Jules & Female & 34 & $\begin{array}{l}\text { In } \\
\text { relationship }\end{array}$ & Unemployed & 3 & S1-L4 \\
\hline Catherine & Female & 61 & Married & Retired & 17 & L5-S1 \\
\hline Michael & Male & 42 & Married & Full time & 5.5 & L1 \\
\hline Fiona & Female & 39 & Married & Full time & 1.5 & L4-L5 \\
\hline Krish & Male & 48 & Married & Full time & 2 & L5-S1 \\
\hline James & Male & 54 & Single & Unemployed & 3.7 & L3-L4 \\
\hline William & Male & 45 & Married & Unemployed & 1.2 & L3-S1 \\
\hline Lily & Female & 56 & Married & Unemployed & 1 & L4-L5 \\
\hline Garry & Male & 52 & Married & Full time & 2 & L4-L5 \\
\hline
\end{tabular}

theme speaks to professional validation and acknowledgement as the antidote to these experiences.

Feeling neglected and disbelieved by the professional network. Five participants spoke about their experiences of presenting to professionals with worsening symptoms before a diagnosis was of CES was made, and feeling disbelieved and 'like I was making up my symptoms' (Michael). This appeared to be disorienting, isolating and frightening as described by Jules:

I think I went back about 12 times...I was having bladder problems, bowel problems....some professionals don't realise or take that into account, he just put it down to my medication was the reason why I was constipated...He didn't examine me, he didn't listen to me, and I came out of there crying. And I said no one's understands what I'm going through.... I said I need to see someone. I need to see someone who understands me.

Regarding post diagnostic and surgical support, there was a strong narrative endorsed by nine participants that 'the aftercare was nonexistent' (Garry), 'no one sat me down and explained it to me' (Michael) and 'not once did I see a continence nurse, not once did I see anybody who could give me any guidelines' (Sally). This was attributed in part to 'the lack of professional understand to it...they knew nothing, absolutely nothing about CES' (Sally). These accounts did however contrast with that of Fiona, who was triaged onto an inpatient spinal unit straight after her operation and who felt that immediate access to treatment and information helped her to better understand and cope with the injury.

A sense of injustice. This subordinate theme refers to a strong sense of anger expressed by five participants, specifically in relation to their care. Two participants had wanted to make a legal claim against the NHS but upon legal advice had not pursued it, while three others were in the process of making a claim. Jules described 'No money will make this better.....but in a way it's opening the doctor's eyes to the mistakes they made. It may help someone else in the future'.

The fact that nearly half of the sample wished to pursue a claim against the NHS in relation to perceived poor treatment is a striking reflection of the strength of their dissatisfaction with both pre- and post-diagnostic care. Of note, this appeared different to a more general sense of injustice directed at the shock of their injury. 
Table 3 Study themes

\begin{tabular}{|c|c|}
\hline Superordinate themes & Subordinate themes \\
\hline Dissatisfaction with care: 'I felt very abandoned' & $\begin{array}{l}\text { Feeling neglected and disbelieved by the professional network } \\
\text { A sense of injustice } \\
\text { Validation from professionals as an antidote }\end{array}$ \\
\hline Hidden to others: 'Nobody knows. It's horrible' & $\begin{array}{l}\text { Being in no man's land } \\
\text { 'Not disabled enough' for support } \\
\text { Fears of being seen inaccurately }\end{array}$ \\
\hline $\begin{array}{l}\text { Renegotiating identities: 'You become someone totally totally different' and } \\
\text { 'You're still the same person' }\end{array}$ & $\begin{array}{l}\text { Initial hopelessness about the future } \\
\text { Symptoms as an affront to self concept } \\
\text { Ambivalence about injury and self } \\
\text { Integrating injury into sense of self }\end{array}$ \\
\hline
\end{tabular}

Validation from professionals as an antidote. Nine participants endorsed this subordinate theme and spoke about how professionals who possessed a therapeutic stance of kindness, validation, acknowledgement and respect were the antidote to participants feeling otherwise overlooked and dissatisfied with care. Krish described that 'I find it more medicinal talking to people than taking medication', suggesting that there is a restorative and healing quality to sharing experiences with others, and feeling heard. Participants who had spent time on a spinal unit explained that 'straight away I felt at home' (Garry), and 'they listen to you....it's like stepping into a different world.... they don't see a disability. They just see you as you.... spent the first day crying because I was like, oh my god, someone knows how I'm feeling' (Jules). These accounts suggest the importance of being cared for in an environment where disability is acknowledged, but at the same time one is seen as a whole person, beyond a disability lens.

\section{Hidden to others: 'Nobody knows. It's horrible'}

This superordinate theme relates to participants' struggle to find an identity in relation to CES. It speaks to the experience of CES as a hidden disability, which is misunderstood by others and prevents access to support. It also captures the experience of feeling unable to fit in with the wider SCI population and anxieties about being misrepresented by objects of disability.

Being in no man's land. All participants endorsed this subordinate theme. It speaks to their struggle to find an identity in relation to CES and captures a sense of being stuck between two positions. The first is a position of feeling disabled, but that hidden symptoms are unacknowledged by society. The second is a position of feeling not 'disabled enough' (Garry) when compared to the wider SCI population.

Krish spoke about CES being 'like a hidden illness'; invisible to the outside world as the core symptoms are internal. Catherine described a sense of loneliness and sadness that 'nobody knows. It's horrible. Because you are walking about... and people think you're alright. Because you look alright'. This is pertinent given that many participants described internal symptoms, such as bladder and bowel problems, as very distressing. This presents a conflict whereby the symptoms of CES are experienced as distressing and severe; yet they are unseen and misunderstood by society. These findings also suggest difficulties in disclosing hidden symptoms, possibly because of feelings of shame or anxiety.

In addition, five participants who spent time on a spinal unit described comparing themselves to people with higher SCIs and 'feeling a fraud because you can walk' (Garry), 'like a fake' (William) and 'guilty...because I wasn't in a wheelchair' (Lily). Participants appeared to undermine the severity of their own injury when comparing themselves with other SCI patients.

'Not disabled enough' for support. Six participants endorsed this subordinate theme and spoke about their struggle to access financial support as a result of hidden symptoms being 'disbelieved' (Fiona), and not being 'disabled enough' (Garry) to be eligible for disability funding. Other participants described a battle involving 'five tribunals' (William) and 'contacting my local MP to help get my assessment done' (Michael). Of note, one participant described these processes as 'debilitating' (Fiona) as barriers to support contributed to barriers to participation. This suggests that barriers to support influenced this participant's sense of being disabled, beyond physical injury alone.

Fears of being seen inaccurately. Five participants endorsed this subordinate theme and described fears that people would judge them by their disability, and be blinded to seeing their identities beyond this. Participants spoke about an anxiety of being misrepresented by objects of disability and 'not wanting to go out, you don't want to see people because I have a stick, I have a knee brace, um, body corsets' (Jules). James also spoke about an anxiety that his identity is reduced 'as if they're not looking at me as a person, I could see them looking at the cane.... I could see the eyes go to the cane, they didn't look at me'.

What is pertinent about these accounts is the prevalence of social anxiety in the sample. When linking this to the superordinate theme as a whole, participants seem to allude to a conflict between being hidden but wanting to be seen, but worrying that when they are seen in society they are seen inaccurately. What appears fundamental to these accounts is a wish to be seen accurately and feel connected and accepted in society.

\section{Renegotiating identities: 'You become someone totally totally different' and 'You're still the same person'}

This superordinate theme relates to the many ways in which participants felt that CES had affected their identity. It captures a non-linear process of adjustment involving feelings of hopelessness and being affronted by injury, to ambivalence about the extent to which they have been changed. In addition, participants described a process of integrating injury into their identity.

Initial hopelessness about the future. Six participants endorsed this subordinate theme and spoke about a sense of hopelessness in the early stages of injury, to the extent that they felt suicidal. They described 'I really wish I could have died because I was totally lost...I couldn't see any future' (Sally), and feeling 'totally totally depressed.... I have contemplated suicide and I've thought well what, what is the 
point?' (Lily). The notion that CES came as a sudden shock in life, where 'one minute you're this person and everything is fine and then you wake up.... and everything is alien to you' (Dawn), implies that participants were confronted with a frightening situation where their expectations of the future were initially shattered. Prior to rebuilding new expectations for the future, participants described feeling lost and disoriented.

Symptoms as an affront to self concept. All participants endorsed this subordinate theme and spoke about how symptoms of CES had affected their identity and assumed roles. Participants communicated a wide range of experiences relating to symptoms. Regarding bladder and bowel dysfunction, participants explained that these were the 'biggest' (Garry), 'toughest' (Michael) and 'worst' (Dawn and Fiona) symptoms of CES. They perceived it as 'degrading' (Sally and Jules), which appeared to elicit a shame and disgust response and a fear of humiliation. Participants also experienced these symptoms as infantilising, describing accidents as 'being a baby again' (Jules).

Regarding sexual dysfunction, James described avoiding conversations with women due to an anxiety about his sexual performance and fears of being sexually unappealing or humiliated. 'What happens if it don't work and I really do like someone and if this spoils it.... if I can't get an erection...I feel at the moment I can't produce that part, so I won't even start to entertain talking to someone'.

Regarding pain, Catherine described being unable to drive 'because it hurts too much', resulting in an experience that 'everything needs to be planned around me..... you can't go and do what you want....it's horrible'. This appeared an affront to her sense of independence and self reliance. Finally, regarding changed mobility and strength namely males in the sample described feeling that their masculinity was affected; that they felt 'emasculated' (William) and 'not a man' (Garry).

These accounts indicate that participants felt, in differing ways, changed by the symptoms of CES, and that this change was not just physical, but related to their identity and self concept. What is poignant is the meaning that they appeared to ascribe to different symptoms e.g. being less of a man or being a baby again, and it is proposed that these ascribed meanings affected self concept and distress, over and above the symptoms themselves.

Ambivalence about injury and self. Six participants endorsed this subordinate theme. It speaks to an internal conflict about whether CES had changed participants as a person, or whether they were still the same after injury. Sally explained that 'a lot of people see me as the same person with an injury. I'm not the same person I was', then later stated 'I would like to think that my personality has remained fairly undamaged'. This conflict is echoed in James' account when he described:

Sometimes I think I'm being stupid (laughs). I do, I think to myself, what's the matter with you, you're still the same person, you've just got something not working that right, that's all, you're still the same person inside or like that....so why worry about it? But you do, you know what I mean?

These accounts suggest mixed feelings about the extent to which CES had changed their identity. Jules also alluded to a wish to reject aspects of her disability. She explained that 'you can get a bus pass and a blue badge, but I still haven't claimed it because that's another thing of oh my god this is real...it's a statement really of disability'. This back and forth between a wish to reject disability, wanting disability to be validated, and questioning whether the self is changed by injury, represents an internal struggle to renegotiate identity after CES.
Integrating injury into sense of self. All participants endorsed this subordinate theme and spoke about a range of ways in which they had learnt to adapt to life with CES. They described what appeared to be two main processes of integrating injury into their sense of self: (1) Changing aspects of their environment to allow them to re-engage with valued identities and activities and (2) adjusting their psychological appraisals of themselves and the world, giving them a new outlook on valued identities and activities.

Regarding the former, participants described practical ways in which they had learnt to manage symptoms such as bladder and bowel function, including 'limiting my drinking' (James) and 'monitoring' timings (Lily). This helped to reduce the frequency of accidents and the extent to which these symptoms intruded upon life. In turn this appeared to increase participants' confidence to re-engage with activities which provided them with a sense of purpose and worth, which alleviated the perception that CES was an affront to their identity.

Regarding the process of adjusting psychological appraisals, Garry describes 'I slowly got to thinking, well.... if it doesn't get any better I can still go to work, I still can provide for my family'. This suggests a reappraisal from a focus on threat and what's lost, to a focus on what is retained, and which roles he can still engage in that give him a sense of purpose and worth. Participants spoke about the role of 'acceptance' (Sally) 'determination' (Dawn) and resilience in terms of 'kinda pushing myself (James) as central to the process of re-appraising.

\section{DISCUSSION}

This study aimed to address the paucity of research into CES and answer the following question: What are the lived experiences of individuals with CES? Findings that participants felt that their prediagnostic symptoms were disbelieved, and that there was a lack of timely post-diagnostic support, are replicated in Greenhalgh et al.'s study. ${ }^{1}$ This highlights a need to increase access to timely pre- and post-diagnostic support and raise professional and public awareness of CES. For individuals who may not present to specialist spinal centres, it is important to consider to which community services they may be referred to and efforts should be made to co-ordinate their treatment as opposed to treating symptoms of CES in isolation. This may encourage a holistic conceptualisation of CES to include the psychosocial impact of symptoms, that is, to self concept and social participation.

Regarding the findings that participants felt their symptoms were overlooked and disbelieved, it is important to acknowledge that CES is a complex injury to assess, and that patients may present with symptoms, such as pain, before they present with symptoms that require an MRI.,12 In this context, it is possible that participants retrospectively felt that their worsening, pre-diagnosis, symptoms were overlooked, despite their treatment being informed by sound clinical judgement. In this instance, it is still imperative that professionals actively validate worsening symptoms and seek to inform CES patients of the complexity of the assessment process. This may help individuals develop a greater sense of coherence about their early experiences of diagnosis. This is important as a sense of coherence is a predictor of positive adjustment to SCI. ${ }^{13}$

However, it is also possible that professionals did disbelieve participants' symptoms of CES as research into other hidden health conditions such as chronic pain and chronic fatigue, indicates that symptoms which are not visible, or are hard to 'prove', can be disbelieved by others and that this can lead to patient distress and anger. ${ }^{14,15}$ This may have contributed to participants' sense of injustice and anger towards the NHS, and could possibly explain high levels of litigation in both this 
sample and the broader CES population. In this context, professionals are encouraged to reflect on their own therapeutic stance and beliefs about CES with the aim of considering the impact their interaction with CES patients may have on experiences of care.

Regarding findings that participants struggled to find an identity in relation to CES and felt like a 'fake' when compared to the wider SCI community, it is interesting to consider the extent to which this perception may have reinforced by other SCI patients, that is, by possible implicit communications of jealousy or messages that they are more fortunate than individuals with higher SCIs. Professionals working in specialist spinal services are encouraged to be aware of the potential for CES patients feeling isolated, particularly given that experiences of social isolation (perceived and actual) are risk factors for depression ${ }^{16}$ and suicide. ${ }^{17}$ Staffs are also encouraged to validate the severity of CES and highlight its similarities with other SCIs. For example, by sharing with patients the research findings that the core symptoms of CES (bladder, bowel and sexual dysfunction) are consistently reported across the SCI population as the most distressing aspects of injury, over and above mobility. ${ }^{2}$ This may help both patients and staff to consider that mobility may not be as defining a difference, in terms of psychological and emotional wellbeing, as may be assumed. Additionally, patients should be supported to think about how to disclose hidden symptoms to others, given that part of what contributes to a sense of them being hidden may be difficulties talking about symptoms that may feel embarrassing or shameful. This is applicable to the wider SCI population, not just patients with CES.

Of note, findings relating to the challenges of having a hidden disability link in a timely fashion with a broader sociopolitical discussion currently being led by the Care Quality Commission's 'Invisible Conditions' campaign in the United Kingdom. ${ }^{18}$ This aims to better understand and challenge inequalities experienced by people with 'invisible' physical and mental health conditions with regards to accessing support.

Finally, findings that psychological appraisals of symptoms mediated the extent to which participants felt changed by their injury is widely replicated across the SCI literature, with appraisals being a strong predictor of adjustment following injury. ${ }^{19}$ In this context, interventions focusing on appraisals and acceptance of injury are of importance. Findings additionally highlight the therapeutic benefit of making environmental changes to enhance engagement with valued identities and activities. This is again replicated across the SCI literature $\mathrm{e}^{20}$ and provides a strong rationale for increasing access to timely post-diagnostic care for people with CES in order to provide appropriate support to facilitate these environmental changes, that is, via advice about incontinence aids and mobility equipment.

\section{Future research and study limitations}

Given that this is the first study to explore the psychosocial impact of CES, there continue to be multiple gaps in the literature. A larger scale study is required to establish the gaps between patient needs and service provision in order to aid service development and further investigate what prompts high rates of litigation in the CES population. Future research would also benefit from considering the influence of pre-injury biopsychosocial factors, such as mental health and personality traits, on adjustment to CES. As this study did not include any measure or question about pre-injury mental health or quality of life in data collection it remains unclear whether the CES injury caused experiences such as social anxiety, or whether injury exacerbated pre-injury experiences. Other lines of enquiry include a comparison of psychosocial outcomes for people with complete versus incomplete CES, as the participants in this study only represent a subpopulation with incomplete lesions.

\section{DATA ARCHIVING}

There were no data to deposit.

\section{CONFLICT OF INTEREST}

The authors declare no conflict of interest.

\section{ACKNOWLEDGEMENTS}

We thank the participants and the staff at Stoke Mandeville Hospital, The Royal National Orthopaedic Hospital and CES-UK who kindly helped us to collect data. Sponsored by Oxford Health NHS Foundation Trust.

1 Greenhalgh S, Yruman C, Webster V, Selfe J. An investigation into the patient experience of Cauda Equina Syndrome: a qualitative study. Physiother Pract Res 2015; 36: 23-31.

2 Simpson L, Eng JJ, Hsieh JTC, Wolfe DL. The health and life priorities of individuals with spinal cord injury: a systematic review. J Neurotrauma 2012; 2: 1548-1555.

3 Pollard C, Kennedy P. A longitudinal analysis of emotional impact, coping strategies and post-traumatic psychological growth following spinal cord injury: a 10-year review. Br J Health Psychol 2007; 12: 347-362.

4 Livneh H, Martz E. Coping strategies and resources as predictors of psychosocial adaptation among people with spinal cord injury. Rehab Psychol 2014; 59: 329-239.

5 Elliott TR, Herrick SM, Witty TE, Godshall F, Spruell M. Social support and depression following spinal cord injury. Rehab Psychol 1992; 37: 37-48.

6 Balasubramanian K, Kalsi P, Greenough CG, Kuskoor Seetharam MP. Reliability of clinical assessment in diagnosing Cauda Equina Syndrome. Br J Neurosurg 2010; 24: 383-386.

7 NHS England. NHS standard contract for spinal cord injuries (all ages) NHS England 2013.

8 National Institute for Health and Care Excellence. Spinal Injury: Assessment and Initial Management (Clinical Guidance 41). NICE: UK. 2016.

9 Daniels EW, Gordon Z, French K, Ahn UM, Ahn NU. Review of medicolegal cases for Cauda Equina Syndrome: what factors lead to an adverse outcome for the provider? Orthopedics 2012; 35: 414-419.

10 Smith JA, Flowers P, Larkin M. Interpretative Phenomenological Analysis: Theory, Method and Research. Sage: London. 2009.

11 Janghorban R, Roudsari RL, Taghipour A. Skype interviewing: the new generation of online synchronous interview in qualitative research. Int J Qualit Stud Health Wellbeing 2014; 9: 1-3.

12 Ferguson F, Holdsworth L, Rafferty D. Low back pain and physiotherapy use of red flags: the evidence from Scotland. Physiotherapy 2010; 96: 282-288.

13 Kennedy $P$, Lude $P$, Elfström ML, Smithson E. Sense of coherence and psychological outcomes in people with spinal cord injury: appraisals and behavioural responses. $\mathrm{Br} \mathrm{J}$ Health Psychol 2010; 15: 611-621.

14 Reid J, Ewan C, Lowy E. Pilgrimage of pain: the illness experiences of women with repetition strain injury and the search for credibility. Soc Sci Med 1991; 32: 601-612.

15 Ware NC. Suffering and the social construction of illness: the delegitimation of illness experience in Chronic Fatigue Syndrome. Med Anthropol Q 1992; 6: 347-361.

16 Cobb S. Social support as a moderator of life stress. Psychosom Med 1976; 38: 300-314.

17 Joiner TEJ, Silva C. In:Shaver P, Mikulincer M (eds) Meaning, mortality, and choice: The social psychology of existential concerns. American Psychological Association: USA. 2012.

18 Care Quality Commission (2016) Invisible conditions. Available at http://www.cqc.org. uk/content/invisible-conditions.

19 Galvin LR, Godfrey HP. The impact of coping on emotional adjustment to spinal cord injury $(\mathrm{SCl})$ : review of the literature and application of a stress appraisal and coping formulation. Spinal Cord 2001; 39: 615-627.

20 Thompson NJ, Coker J, Krause JS, Henry E. Purpose in life as a mediator of adjustment after spinal cord injury. Rehab Psychol 2003; 48: 100-108. 